Crash patterns at signalized intersections

Peer-reviewed author version

POLDERS, Evelien; DANIELS, Stijn; HERMANS, Elke; BRIJS, Tom \& WETS, Geert (2015) Crash patterns at signalized intersections. In: TRANSPORTATION RESEARCH RECORD (2514), p. 105-116.

DOI: $10.3141 / 2514-12$

Handle: http://hdl.handle.net/1942/18429 


\title{
Crash Patterns at Signalized Intersections
}

\author{
Authors: \\ Evelien Polders, Stijn Daniels, Elke Hermans, Tom Brijs and \\ Geert Wets $^{\circ}$ \\ ${ }^{\circ}$ Corresponding author \\ Transportation Research Institute (IMOB), Hasselt University \\ Wetenschapspark 5/6, 3590 Diepenbeek, Belgium \\ Fax: +32(0)11269199 \\ Tel.: +32(0)11 $2691--\{44 ; 56 ; 41 ; 55 ; 58\}$ \\ E-mail: \{evelien.polders; stijn.daniels; elke.hermans; tom.brijs; geert.wets $\} @$ uhasselt.be
}

First submitted: July $31^{\text {st }}, 2014$

Revised paper submitted: November $14^{\text {th }}, 2014$

\author{
Word counts: \\ Abstract 246 \\ Body of paper 5754 \\ Figures $\left(\mathrm{NF}^{* 250)} \quad 2 * 250 \quad 500\right.$ \\ Tables $(\mathrm{NT} * 250) \quad 2 * 250 \quad 500$ \\ Photographs (NP*250) $0 * 250 \quad 0$ \\ References (not included) 1372 \\ $\begin{array}{ll}\text { Total } & 7000\end{array}$
}




\begin{abstract}
Traffic signals are often implemented to provide for efficient movement and to improve traffic safety. Nevertheless, severe crashes still occur at signalized intersections. This study aims to improve the understanding of signalized intersection safety by identifying crash types, locations and factors associated with signalized intersections. For this purpose, 1295 police-reported crashes at 87 signalized intersections are analyzed based on detailed crash descriptions, i.e. crash data and collision diagrams. The information of the collision diagrams is used to distinguish six different crash types and to create a crash location typology to divide the signalized intersection into 13 detailed and different typical segments. Logistic regression modeling techniques are used to identify relations between crash types, their crash location on certain signalized intersection segments, the crash severity and the different features that affect their crash occurrence. Four dominant crash types are identified: rear-end, side (i.e. left-turn + right-angle), head-on and VRU crashes. The results of the logistic regression models showed that the crash location of these crash types is related to specific signalized intersection segments. The results also reveal important signalized intersection features that affect the crash occurrence. As a result, connections between certain signalized intersection crash types, their crash location and signalized intersection design characteristics have been found. The combination of intersection features with detailed signalized intersection segments provides valuable insights in the nature of signalized intersection crashes and the safety impact of signalized intersection design.
\end{abstract}

18

Keywords: crash types, crash location, collision diagram, signalized intersection, logistic regression 


\section{INTRODUCTION}

Intersections are crash prone locations since they are characterized by many conflicting movements, resulting in complexity and large variations in interactions between road users. To minimize the number of conflicts at intersections and to increase traffic safety, intersections are often equipped with traffic signals (1). Despite the fact that traffic signals separate movements in space and time, crashes at these intersections still occur. In Flanders, Belgium approximately $8 \%$ of all injury crashes occur at signalized intersections representing $4 \%$ of all road deaths (2). However, equipping intersections with traffic lights can also induce side effects. Traffic signals can change the crash pattern at intersections by decreasing head-on and angle crashes while increasing rear-end crashes $(3,4)$. Subsequently, traffic lights also give rise to red light running crashes which tend to be more severe since they typically occur at high speeds (3).

Previous studies identified four dominant crash types at signalized intersections: rear-end, angle, sideswipe and vulnerable road user crashes (5-8). Crashes with vulnerable road users and angle crashes are of a more severe nature and result more often in deadly or severely injured road users while sideswipe and rear-end crashes have a less serious outcome resulting in crashes with material damage or slight injuries $(5,9,10)$.

Several studies have also studied the relation between signalized intersection design and crash occurrence. The presence or absence of several signalized intersection design characteristics appears to have a beneficial or adverse effect on the traffic safety of these locations. The total number of lanes is positively related to the number of crashes (6). However, exclusive right-turn and left-turn lanes have a positive effect on traffic safety since they reduce the total number of crashes while exclusive right-turn lanes (in countries with righthand traffic) also lead to a decrease in rear-end crashes $(5,11)$. Medians lead to lower crash severity levels since they prevent more severe head-on crashes (9). Signalized intersection speed limits play an important role in the total number of crashes, angle crashes, left-turn crashes, head-on crashes, rear-end collisions and crashes with vulnerable road users (VRU) $(9,12)$. In general, red light cameras tend to increase the number of rear-end crashes and decrease the occurrence of side crashes (i.e. left-turn + right-angle crashes)(13-15). Protected-only and protected/permitted left-turn signal phasing lead to substantial decreases in the number of injury and severe injury crashes at signalized intersections (16). These types of signal phasing also have a favorable effect on left turn crashes (16-17). VRU facilities also influence traffic safety at signalized intersections. At signalized intersections with low vehicle speeds and volumes, mixing cyclists with motorized traffic at the intersection has been reported to be the safest solution (18). Pedestrian safety at signalized intersections has been found to depend on the number of lanes. The more lanes pedestrians must cross, the higher the number of pedestrian crashes (19).

\section{STUDY OBJECTIVE}

A lot of studies have already focused on the road safety performance of signalized intersections. However, little is known about the exact location of the crashes. Therefore, the present study focuses on identifying and analyzing the crash patterns at signalized intersections by using detailed information about the location of the crash. Gstalter and Fastenmeier (20) analyzed driver errors by dividing intersections in segments according to the tasks that drivers should perform in each segment. We elaborated on this approach and tried to delineate the crash location on the signalized intersection itself in more detail to gain a better insight into the crash patterns and their exact location. This method identifies the dominant crash type inside each segment and enables to link the crash occurrence with design characteristics of the signalized intersection. As a result, the findings of this study result in a detailed description of the crash patterns at signalized intersections which provides insights into the safety impact and possible safety issues of this intersection design. Other studies have also applied the same or similar methods to other locations including stop sign controlled intersections (21), roundabouts (22), freeway ramps (23) and work zone crashes (24).

\section{METHOD}

\section{Data}

Crash Data

In this study, the crashes were sampled from police-reported crashes at 87 signalized intersections in the region of Flanders, Belgium. The national crash database could not be used since it does not contain detailed information about the crash location at the signalized intersection. Therefore, several police zones were selected 
that systematically register more detailed crash location information. Ultimately, 12 police zones were able to provide the requested data. This approach resulted in a convenience sample of signalized intersection locations.

The crashes occurred in the period 2007-2011. Crash data were available for each year and for every sampled signalized intersection in this entire period. In total, 1344 crash reports containing injury and propertydamage-only crashes were obtained. These police reports provided basic (such as time, place of occurrence, weather/light conditions) and detailed (such as crash type and location) information about the registered crashes. The detailed crash information, in the form of collision diagrams, was used to develop crash types. A collision diagram is a schematic representation of all crashes that occurred at a given signalized intersection or other location over a specific period (3). This diagram indicates the dominant crash types at a signalized intersection and the maneuvers that led to these crashes while providing detailed information about the crash location at the intersection.

\section{Intersection Design and Usage Data}

Crash data only are not sufficient to provide insights in the crash patterns at signalized intersections. It is also important to know the crash location in terms of roadway and traffic data in order to gain a full understanding of the traffic safety situation. These factors may affect the crash occurrence. Roadway data aid in detecting the physical and use characteristics of the location which may have contributed to the crash occurrence or severity while traffic volume data are used to control for use intensity of the location (25).

Based on a literature review $(6,26,27)$, the most relevant signalized intersection characteristics were selected as they appear from previous crash prediction model studies. They include the number of arms, the presence of exclusive turn lanes, the number of lanes, built-up area, the type of bicycle infrastructure, the presence of a median, the speed limit, the signal phasing, crossings for vulnerable road users, the presence of a bypass and red light camera. Traffic volume data were available for 54 of 87 sampled signalized intersections. The traffic volumes in the data are expressed in AADT (annual average daily traffic). No data were available for exposure by type of road user and the actual driving speeds at the signalized intersection. A detailed description of intersection characteristics is provided in table 1.

\section{Signalized Intersection Segments}

The detailed crash location was included by dividing the signalized intersections into different typical segments, according to previously established knowledge on the crash occurrence and road user behavior at signalized intersections $(5-7,13,20)$. Figure 1 depicts the selected 13 segments. The segments can be described as follows:

- Segment 1: 20-100 meters off the signalized intersection. Oncoming traffic, queues associated with congestion.

- Segment 2: 20 meters before the intersection plane until the stop line.

- $\quad$ Segment 3: exclusive left turn lane (if present).

- Segment 4: first half of the intersection plane. Pedestrian and cyclist crossings.

- Segment 5: second half of the intersection plane for traffic going straight ahead.

- Segment 6: second half of the intersection plane for traffic turning left.

- $\quad$ Segment 7: location until 20 meters after the junction plane for right turning leaving traffic. Pedestrian and cyclist crossings.

- $\quad$ Segment 8: identical to segment 7, but for traffic going straight ahead.

- $\quad$ Segment 9: identical to segment 7, but for left turning leaving traffic.

- Segment 10: location 20-100 meters after the intersection plane. Leaving traffic.

- Segment 11: the beginning of the bypass, if present.

- Segment 12: the middle section of the bypass, including pedestrian and cyclist crossings, if present.

- $\quad$ Segment 13: the end section of the bypass until the yield markings.

Segments 11-13 are optional and are only relevant when the signalized intersection is characterized by a bypass. 


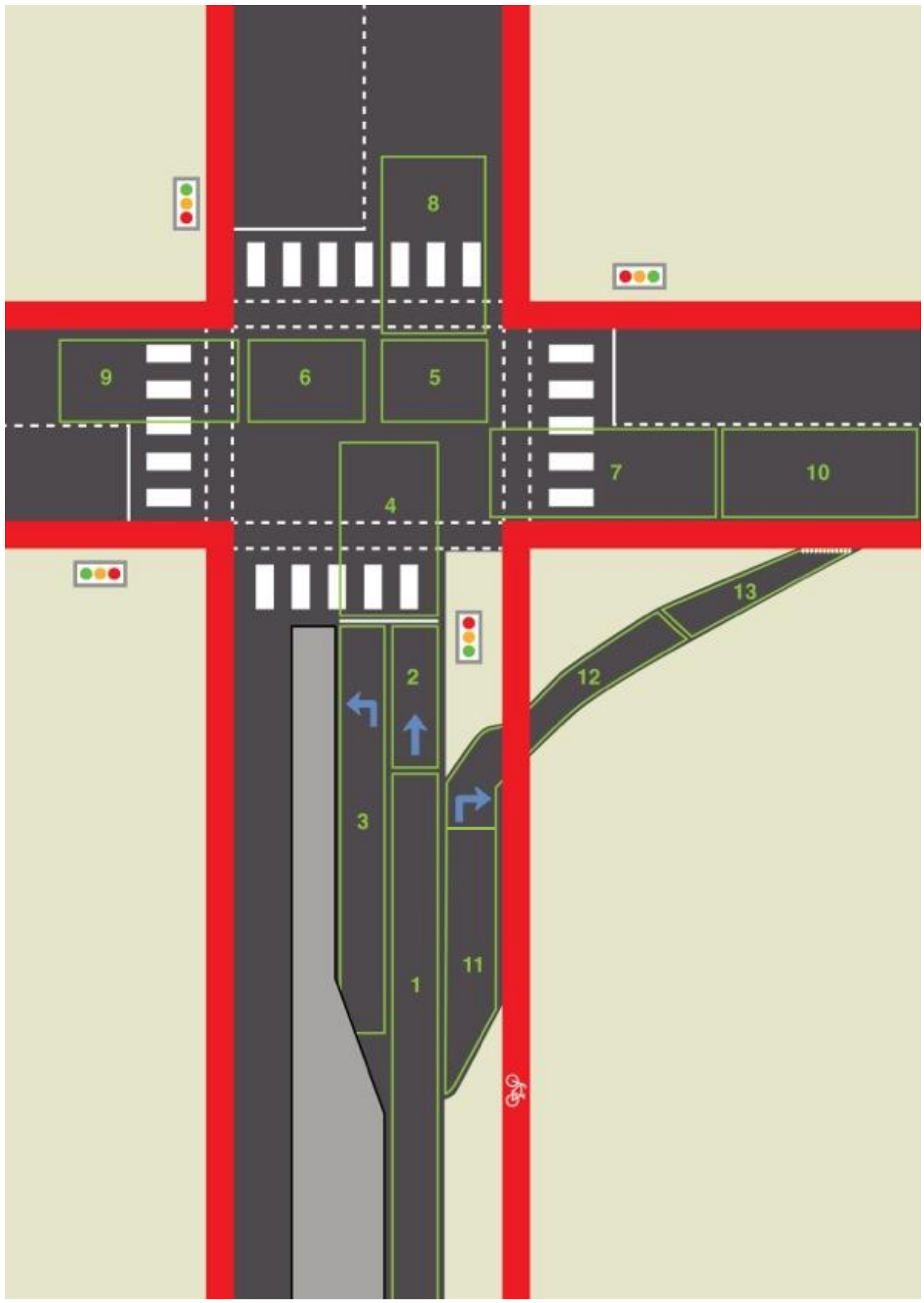

Figure 1 Signalized intersection segments. 
Figure 1 is a representation of a typical signalized intersection. The segments were defined in such a way that the variety of real-world designs is represented by the figure and meaningful analyses based on the defined standard segments are possible. To capture all possible designs, a sort of 'maximal design' was used, representing a typical signalized intersection lay-out with some extra features that are not necessarily always present. For example, a bypass lane was added in order to include also crashes that happen on bypass lanes at certain intersections. This means that only crashes at segments 11-13 must be registered in case of a signalized intersection with such a bypass lane. The same applies for the cycle facilities (cycle paths and cycle crossings): pedestrian or bicyclist crossings at real-world intersections occur in different varieties. This means that, whereas the figure is representing an adjacent cycle path, the real distance between the cycle facility and the roadway may vary between 0-10 meter and grade-separated. This principle applies also to the number of lanes and the number of intersection legs.

\section{Crash Location Typology}

A crash typology was created to assign the crashes to the segments in figure 1. This typology is based on the crash typology of Massie, Campbell \& Blower (28) who identified different crash scenarios between motorized vehicles based on crash data and collision diagrams.

The first step involved revising the crash data and collision diagrams to select the variables that seemed most useful to develop a crash location typology. The main focus of this review was on the pre-crash movements of the involved road users. The selected variables of the initial review were used to build a preliminary crash location typology, which was modified by adding and deleting variables until the final crash location typology scheme, as depicted in figure 2, was produced. This typology is applicable for crashes between motorized road users, between motorized and vulnerable road users and between vulnerable road users.

The southern intersection approach in figure 1 was used as analysis unit. Each crash was localized by starting from this intersection approach. The road user who makes the pre-crash maneuver/movement always approaches the intersection from this side. The maneuvering road user is based on the schematic representation of the crash in the collision diagrams.

The final crash location typology includes the number of road users involved in the crash, the location of the impact point, the relative pre-crash orientation of the road users and the movement of the road user who makes the maneuver. Figure 2 provides an overview of the typology. The crashes were first split according to whether the road user was involved in a crash with only one or multiple road users (step 1). These two groups were then divided based on whether the crash took place before, after, at the intersection plane or at the bypass (step 2). Multi-road user crashes were split into three categories: road users approaching each other from the same direction prior to the crash, road users approaching from opposite directions and road users approaching on crossing paths (step 3). Subsequently, the single- and multiple road user crashes were further split according to whether the maneuvering road user was moving straight ahead or attempted to make a left-, right- or U-turn (step 4). Finally, the resulting subgroups were assigned to the crash location expressed as segments 1-13 in figure 1 (step 5). Steps 4 and 5 are combined in figure 2 for visualization purposes. 


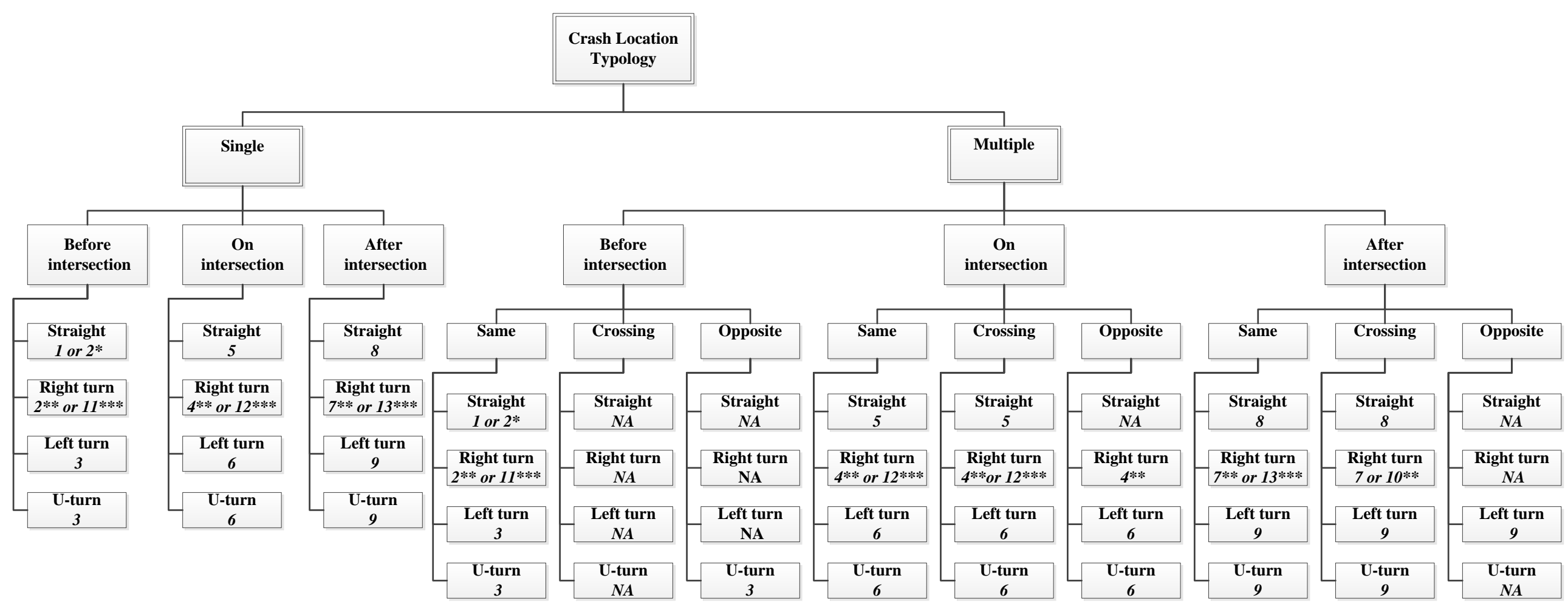

1 Figure 2 Crash location typology.

Numbers in bold and italic represent intersection segment

$N A$ : no segment available (not every manoeuvre can occur on each segment)

*Depends on distance to intersection

**For intersections without bypasses

***For intersections with bypasses 


\section{Crash Data Analysis}

\section{Logistic Regression Models}

Several studies previously applied logistic regression analysis to test the influence of traffic crash risk factors (29-33). In this study the occurrence of certain dominant crash types at signalized intersections can be considered as a binary response variable. Therefore, logistic regression analysis was used to predict the probability of a certain event. This analysis also allows to test the relation between the dominant crash types and their crash location on the signalized intersection. The structure of the fitted logistic regression models was the following (34):

$$
\operatorname{logit}(\mathrm{P})=\ln \left(\frac{P}{1-P}\right)=\beta_{0}+\beta_{1} \mathrm{x}_{1}+\beta_{2} \mathrm{x}_{2}+\cdots+\beta_{\mathrm{n}} \mathrm{x}_{\mathrm{n}}
$$

where $P$ is the probability of dominant crash types, $\mathrm{x}_{\mathrm{n}}$ is the independent variable and $\beta_{\mathrm{n}}$ are the partial logistic regression coefficients.

The odds of each dominant crash type were defined as the probability of this specific dominant crash type occurring divided by the probability of all other signalized intersection crash types occurring. Odds ratios $\left(\mathrm{OR}=\operatorname{Exp}\left(\beta_{\mathrm{n}}\right)\right)$ were calculated to determine the rate of decrease $(0 \leq \mathrm{OR}<1)$ or increase $(\mathrm{OR}>1)$ of the probability of the outcome when the value of the independent variables increases with one unit (35). Firth's penalized maximum likelihood was applied to overcome the most common convergence failure in logistic regression, namely the problem of quasi-complete separation $(34,36)$. The logistic regression models were developed by the use of the LOGISTIC-procedure in SAS 9.3 and the variables identified in the literature as having a significant impact on signalized intersection crashes were added first. Crash reports with missing data were omitted from the models resulting in 1295 complete crash records. The model fit was assessed with the Hosmer and Lemeshow test which indicates if the final model provides a better fit than the null model. If the chi-square goodness-of-fit is not significant at CI 95\%, the model has an adequate fit. Since this statistic, gives no indication of the error reduction of the final model, Nagelkerke's $\mathrm{R}^{2}$ was also used. The Variance Inflation Factor (VIF) was used to identify multicollinearity between the predictor variables. According to O'Brien (37), VIF's higher than 4 indicate a high correlation between variables. Since all variables in the end models had VIF's below this threshold there are no multicollinearity issues in the presented models.

\section{RESULTS}

\section{Descriptive Statistics}

All crashes within $100 \mathrm{~m}$ from the center of the intersection were included in the analysis to ensure that all crashes related to the signalized intersection are incorporated in the dataset. Descriptive statistics of the crash data are presented in Table 1 . The registered crashes at the study locations were mostly injury crashes $(53 \%, 699$ out of 1295). The variable "Segment" indicates that most crashes occur in segments 1,2 and 4 before the intersection plane and on segment 6 of the intersection plane where left turning traffic conflicts with oncoming vehicle streams. Segments 11-13 on the bypass seem to be less prone for crashes. This may be due to the small share of signalized intersections with a bypass $(\mathrm{N}=29)$ in the police data.

The crashes were categorized into six different crash types: rear-end, head-on, sideswipe, singlevehicle, pedestrian and side crashes. Three main crash types can be considered as the dominant crash types rear-end, side crashes (left-turn + right-angle crashes) and head-on crashes - since they accounted for $77 \%$ of the signalized intersection crashes. In general, these three crash types typically take place between motorized road users. This is also the case in this study since respectively $96 \%, 74 \%$ and $85 \%$ of the involved roads users in rear-end, side and head-on crashes were motorized road users. Unlike pedestrians, no separate crash type was developed for cyclists, since the action radius of cyclists is larger than for pedestrians. Therefore, the 150 registered cyclist crashes were divided over the six defined crash types. The majority of cyclist crashes were side $(71 \%)$ and head-on collisions $(14 \%)$. The other crash types - single-cyclist $(5 \%)$, rear-end $(8 \%)$, pedestrian $(1 \%)$ and sideswipe crashes $(1 \%)$ - occurred less frequently. 
TABLE 1 Descriptive Statistics

\begin{tabular}{|c|c|c|}
\hline Variable Name & Variable Description & $\begin{array}{c}\text { Signalized Intersection } \\
\left(\mathrm{N}_{\text {locations }}=87, \mathrm{~N}_{\text {crashes }}=1295\right)\end{array}$ \\
\hline \multicolumn{3}{|l|}{ Crash variables } \\
\hline Injury crash & $\begin{array}{l}\text { The crash type with regard to the crash } \\
\text { outcome }\end{array}$ & $\begin{array}{l}\text { Property damage only }=596, \text { Injury } \\
\text { crash }=699\end{array}$ \\
\hline Crash severity & $\begin{array}{l}\text { The crash severity is determined by the most } \\
\text { severe casualty }\end{array}$ & $\begin{array}{l}\text { No injuries }=596, \text { Dead }=7, \\
\text { Severely injured }=64, \text { Slightly } \\
\text { injured }=628\end{array}$ \\
\hline Road user & $\begin{array}{l}\text { Type of involved road user. Frequencies } \\
\text { expressed at subject level }\end{array}$ & $\begin{array}{l}\text { Car }=2098, \text { Truck }=105, \text { Bus }=27, \\
\text { Motorcycle }=48, \text { Moped }=100, \\
\text { Cyclist }=162, \text { Pedestrian }=42 \text {, Other } \\
=70\end{array}$ \\
\hline Crash & $\begin{array}{l}\text { Crash type according to number of involved } \\
\text { road users }\end{array}$ & Single $=130$, Multiple $=1165$ \\
\hline Crash type & $\begin{array}{l}\text { Crash type according to collision angle }\left(0^{\circ} \text {, }\right. \\
\left.90^{\circ}, 180^{\circ}\right)\end{array}$ & $\begin{array}{l}\text { Single vehicle }=130, \text { Head-on }\left(180^{\circ}\right) \\
=181, \text { Rear-end }\left(0^{\circ}\right)=471, \\
\text { Pedestrian }=41 \text {, Sideswipe }\left(45^{\circ}\right)= \\
121 \text {, Side crash }\left(90^{\circ}\right)=351\end{array}$ \\
\hline Segment & $\begin{array}{l}\text { The location of the crash expressed as one of } \\
\text { the segments (seg.) of figure } 1\end{array}$ & $\begin{array}{l}\text { Seg. } 1=103 \text {, Seg. } 2=301 \text {, Seg. } 3= \\
97 \text {, Seg. } 4=214 \text {, Seg. } 5=71 \text {, Seg. } 6= \\
187 \text {, Seg. } 7=79 \text {, Seg. } 8=62 \text {, Seg. } 9 \\
=66 \text {, Seg. } 10=36 \text {, Seg. } 11=8 \text {, Seg. } \\
12=33 \text {, Seg. } 13=38\end{array}$ \\
\hline Vulnerable road user (VRU) & $\begin{array}{l}\text { Crash in which at least one VRU is involved } \\
\text { Pedestrians, cyclists, mopeds and } \\
\text { motorcyclists are VRUs }\end{array}$ & Yes $=268$, No $=1027$ \\
\hline \multicolumn{3}{|l|}{ Intersection Design Variables } \\
\hline Arms & Number of intersection arms & $3=201(22), 4=1094(65)$ \\
\hline Lanes & $\begin{array}{l}\text { Total number of lanes at the intersection } \\
\text { In case of different situations at the } \\
\text { intersection arms, the highest number of lanes } \\
\text { is applied }\end{array}$ & $\begin{array}{l}1=90(12), 2=434(39), 3=379 \\
(26), 4=392(10)\end{array}$ \\
\hline Exclusive right & $\begin{array}{l}\text { Presence of an exclusive right turn lane at the } \\
\text { intersection (at least on one intersection arm) }\end{array}$ & Yes $=455(63)$, No $=840(24)$ \\
\hline Exclusive left & $\begin{array}{l}\text { Presence of an exclusive left turn lane at the } \\
\text { intersection (at least on one intersection arm) }\end{array}$ & Yes $=1186(72)$, No $=109(15)$ \\
\hline Built-up area & $\begin{array}{l}\text { Location of the intersection in terms of inside } \\
\text { or outside built-up area }\end{array}$ & Yes $=581(50)$, No $=714(37)$ \\
\hline Median & $\begin{array}{l}\text { Presence of a median at the intersection } \\
\text { In case of different situations at the } \\
\text { intersection arms = "Yes" }\end{array}$ & Yes $=930(50)$, No $=365(37)$ \\
\hline
\end{tabular}




\begin{tabular}{|c|c|c|}
\hline Speed limit & Speed limit at the intersection & $\begin{array}{l}50 \mathrm{~km} / \mathrm{h}=442(42), 70 \mathrm{~km} / \mathrm{h}=414 \\
(31), 90 \mathrm{~km} / \mathrm{h}=439(14)\end{array}$ \\
\hline Cycle facility & $\begin{array}{l}\text { Type of cycle facility at the intersection } \\
\text { In case of different situations at the } \\
\text { intersection arms, the highest cycle facility } \\
\text { type is applied }\end{array}$ & $\begin{array}{l}\text { Mixed }=30(4), \text { Cycle lanes }=507 \\
(39), \text { Separated }=554(40), \\
\text { Grade-separated }=204(4)\end{array}$ \\
\hline Pedestrian crossing & $\begin{array}{l}\text { Presence of a pedestrian crossing at the } \\
\text { intersection } \\
\text { In case of different situations at the } \\
\text { intersection arms= "Yes" }\end{array}$ & Yes $=1092(81)$, No $=203(6)$ \\
\hline Cyclist crossing & $\begin{array}{l}\text { Presence of a cyclist crossing at the } \\
\text { intersection } \\
\text { In case of different situations at the } \\
\text { intersection arms= "Yes" }\end{array}$ & Yes $=815(52)$, No $=480(35)$ \\
\hline Signal phasing & $\begin{array}{l}\text { The type of signal phasing at the intersection } \\
\text { (for left turns) }\end{array}$ & $\begin{array}{l}\text { Protected-only }=301(12), \\
\text { Protected/permitted }=236(13), \\
\text { Permitted }=758(62)\end{array}$ \\
\hline Bypass & $\begin{array}{l}\text { Presence of a bypass at the intersection } \\
\text { In case of different situations at the } \\
\text { intersection arms= "Yes" }\end{array}$ & Yes $=712(29)$, No $=582(58)$ \\
\hline Red light camera (RLC) & $\begin{array}{l}\text { Presence of a red light camera at the } \\
\text { intersection (at least in one direction) }\end{array}$ & Yes $=657(31)$, No $=638(56)$ \\
\hline Traffic volume & $\begin{array}{l}\text { The traffic volume at the intersection } \\
\text { Expressed in } A A D T\end{array}$ & $\begin{array}{l}\text { Mean }=30959.66 \\
\text { S.D. }=11960.80 \\
\text { Min. }=14561.73 \\
\text { Max. }=67497.13\end{array}$ \\
\hline
\end{tabular}

\section{Logistic Regression Results}

Table 2 presents the factors that influence dominant signalized intersection crash types. These models present the factors that affect the probability that one of these dominant crash types occur. The dependent variable was the probability that a specific dominant crash type occurred over the entire five-year period from 2007-2011.

The results show that the probability of an injury increases in case of side crashes, head-on crashes and crashes with vulnerable road users while single-vehicle crashes result significantly less in injury crashes. The injuries are also more severe in crashes involving vulnerable road users.

The crash types seem to be related to certain signalized intersection segments. Injury crashes are more likely on segments 4, 5 and 6, being the segments on the intersection plane than on segments 3, 10 and 13 . Crashes before the intersection plane (segments 1-3) and on the bypass (segments 11-13) are more likely rearend crashes than crashes on and after the intersection plane (respectively segments 5-6 and segments 7 and 10). Side crashes are more likely on the intersection plane (segments 4-8) than before (segments 1-3) and after the intersection plane (segment 10). Crashes on the intersection plane (segments 4-6) are also more likely head-on crashes than crashes before the intersection plane (segments 1-2). The probability for crashes with vulnerable road users is higher on the crossing facilities after the intersection plane (segments 7-8) and on the bypass (segment 12) than before (segments 1-3) and on the intersection plane (segments 5-6).

The type of left-turn signal phasing also influences the probability of certain dominant crash types. Injury crashes are less likely at intersections with protected-only and protected/permitted signal phasing (compared with the standard permitted signal phasing). Rear-end, head-on and vulnerable road user crashes are less likely at signalized intersections with protected-only signal phasing. Vulnerable road user crashes are also less likely at signalized intersections with protected/permitted signal phasing while the probability of rear-end 
crashes increases. The odds of head-on crashes seem to non-significantly decrease at signalized intersections with protected/permitted signal phasing.

Moreover, the signalized intersection layout affects the odds of certain dominant crash types. The probability of an injury crash decreases at signalized intersections with an exclusive lane for right turning traffic and rear-end crashes appear to be more likely at signalized intersections with 3 arms. Furthermore, rear-end and vulnerable road user crashes appear to be less likely at signalized intersections with two lanes while vulnerable road user crashes also are significantly more likely at signalized intersections with three lanes. Rear-end and head-on crashes are less likely at signalized intersections with medians.

Side crashes are more likely at signalized intersections located inside built-up areas while the probability of head-on crashes decreases.

Furthermore, injury crashes are less likely at $50 \mathrm{~km} / \mathrm{h}$ intersections (compared with 70 and $90 \mathrm{~km} / \mathrm{h}$ intersections) while vulnerable road user crashes are more likely at $50 \mathrm{~km} / \mathrm{h}$ intersections and less likely at 70 $\mathrm{km} / \mathrm{h}$ intersections (compared with $90 \mathrm{~km} / \mathrm{h}$ intersections). Crashes with vulnerable road users also appear to be more likely at signalized intersections where cycle traffic is mixed with motorized traffic.

Enforcement cameras at signalized intersections also appear to affect certain crash types since the presence of a red light camera decreases the probability of side, head-on and vulnerable road user crashes.

The results of the logistic regression models were not able to reveal all characteristics of the dominant crash types. No meaningful models could be fit for sideswipe $(\mathrm{N}=121)$ and single-vehicle crashes $(\mathrm{N}=130)$. However, sideswipe crashes occur significantly more on the left turn lane in segment $3\left(\left(\chi^{2}(1, \mathrm{~N}=1295)=\right.\right.$ $62.734, \mathrm{p}<0.0001)$ and on segment 10 where the vehicles from the bypass merge with oncoming traffic $\left(\left(\chi^{2}(1\right.\right.$, $\mathrm{N}=1295)=18.729, \mathrm{p}<0.0001)$, while segment 1 before the intersection $\left(\chi^{2}(1, \mathrm{~N}=1295)=8.846, \mathrm{p}=0.0003\right)$, segment 8 after the intersection $\left(\chi^{2}(1, \mathrm{~N}=1295)=30.747, \mathrm{p}<0.0001\right)$, segment 9 after the intersection $\left(\chi^{2}(1\right.$, $\mathrm{N}=1295)=31.801, \mathrm{p}<0.0001)$ and segment 12 on the bypass $\left(\chi^{2}(1, \mathrm{~N}=1295)=7.088, \mathrm{p}=0.016\right)$ are characterized by significantly more single-vehicle crashes. The results of the descriptive statistics also revealed that rear-end and sideswipe crashes occur significantly more at red light camera signalized intersections while single-vehicle, pedestrian, head-on and side crashes dominate non-red light camera signalized intersections $\left.\left(\chi^{2}(5, \mathrm{~N}=1295)=66.986, \mathrm{p}<0.0001\right)\right)$. Significantly more crashes occur before the intersection (segments $\left.2-3\right)$ and on/near the bypass (segments 10-13) for red light camera signalized intersections while non-red light camera signalized intersections are characterized by significantly more crashes at segment 1 before the intersection and segments 4-9 on and after the intersection $\left.\left(\chi^{2}(12, \mathrm{~N}=1295)=57.940, \mathrm{p}<0.0001\right)\right)$. 
TABLE 2 Factors Influencing Probability of Signalized Intersection Crash Types

\begin{tabular}{|c|c|c|c|c|c|c|}
\hline \multirow[t]{2}{*}{ Variables $^{1}$} & \multicolumn{6}{|c|}{ Logistic regression results at crash level $(\mathrm{N}=1295)$} \\
\hline & $\begin{array}{l}\text { Injury crashes }^{\mathrm{a}} \\
\text { according to crash } \\
\text { type }(\mathrm{Y}=699)\end{array}$ & $\begin{array}{l}\text { Injury crashes }^{\mathrm{a}} \\
\text { according to crash } \\
\text { location } \\
(\mathrm{Y}=699) \\
\end{array}$ & $\begin{array}{l}\text { Rear-end crashes } \\
\quad(\mathrm{Y}=471)\end{array}$ & $\begin{array}{l}\text { Side crashes }{ }^{\mathrm{b}} \\
(\mathrm{Y}=351)\end{array}$ & $\begin{array}{l}\text { Head-on crashes } \\
\quad(Y=181)\end{array}$ & $\begin{array}{l}\text { VRU } \text { crashes }^{\mathrm{c}} \\
(\mathrm{Y}=268)\end{array}$ \\
\hline Intercept & $0.6719 * * *$ & $0.8753 * * *$ & $-1.2603 * * *$ & $-1.5545 * * *$ & $-3.2815 * * *$ & $-0.3506^{\circ}$ \\
\hline \multicolumn{7}{|c|}{ Crash type (ref = sideswipe) } \\
\hline Single vehicle & $-0.9745(\mathbf{0 . 3 8})^{* * *}$ & & & & & \\
\hline Head-on & $0.8965(\mathbf{2 . 4 5})^{* * *}$ & & & & & \\
\hline Rear-end & $-0.0396(0.96)^{\circ}$ & & & & & \\
\hline Side & $0.6679(\mathbf{1 . 9 5})^{* * * *}$ & & & & & \\
\hline Pedestrian & $0.6527(1.92)^{\circ}$ & & & & & \\
\hline \multicolumn{7}{|c|}{ Segment $($ ref $=$ segment 9) } \\
\hline Segment 1 & & $0.00209(1.00)^{\circ}$ & $1.7636(\mathbf{5 . 8 3})^{* * *}$ & $-0.6957(\mathbf{0 . 5 0})^{* * *}$ & $-1.3791(0.25)^{*}$ & $-0.7382(\mathbf{0 . 4 8})^{* * *}$ \\
\hline Segment 2 & & $-0.091(0.91)^{\circ}$ & $2.7385(\mathbf{1 5 . 4 6})^{* * *}$ & $-3.7433(\mathbf{0 . 0 2})^{* * * *}$ & $-2.4178(\mathbf{0 . 0 9})^{* * *}$ & $-2.1688(\mathbf{0 . 1 1})^{* * * *}$ \\
\hline Segment 3 & & $-0.7963(\mathbf{0 . 4 5})^{* * *}$ & $1.4328(\mathbf{4 . 1 9}) * * *$ & $-2.5073(\mathbf{0 . 0 8})^{* * * *}$ & $-0.7805(0.46)^{\circ}$ & $-1.3573(\mathbf{0 . 2 6})^{* * * *}$ \\
\hline Segment 4 & & $0.5328(\mathbf{1 . 7 0})^{* * *}$ & $-0.1245(0.88)^{\circ}$ & $1.545(\mathbf{4 . 6 8})^{* * *}$ & $1.4759(4.37)^{* * *}$ & $0.1931(1.21)^{\circ}$ \\
\hline Segment 5 & & $0.9915(\mathbf{2 . 7 0})^{* * *}$ & $-2.1494(\mathbf{0 . 1 2}) * * *$ & $2.799(\mathbf{1 6 . 4 2})^{* * *}$ & $1.0755(\mathbf{2 . 9 3})^{* * * *}$ & $-1.0304(\mathbf{0 . 3 6})^{* * * *}$ \\
\hline Segment 6 & & $0.7509(\mathbf{2 . 1 2})^{* * *}$ & $-3.6358(\mathbf{0 . 0 3}) * * *$ & $0.9333(\mathbf{2 . 5 4})^{* * *}$ & $3.3968(\mathbf{2 9 . 8 7}) * * *$ & $-1.1661(\mathbf{0 . 3 1})^{* * * *}$ \\
\hline Segment 7 & & $-0.092(0.91)^{\circ}$ & $-1.6861(\mathbf{0 . 1 9})^{* * *}$ & $1.9607(\mathbf{7 . 1 0})^{* * *}$ & $0.1590(1.17)^{\circ}$ & $2.3335(\mathbf{1 0 . 3 1})^{* * * *}$ \\
\hline Segment 8 & & $-0.0188(0.98)^{\circ}$ & $-0.3096(0.73)^{\circ}$ & $1.1573(\mathbf{3 . 1 8})^{* * * *}$ & $0.1479(1.16)^{\circ}$ & $1.3144(\mathbf{3 . 7 2})^{* * *}$ \\
\hline Segment 10 & & $-0.8600(\mathbf{0 . 4 2})^{*}$ & $-1.6962(\mathbf{0 . 1 8})^{* * *}$ & $-2.6337(\mathbf{0 . 0 7})^{* *}$ & $-1.3188(0.27)^{\circ}$ & $0.00919(1.01)^{\circ}$ \\
\hline Segment 11 & & $0.9540(2.60)^{\circ}$ & $1.5628(4.77)^{* *}$ & $0.7828(2.19)^{\circ}$ & $-0.1309(0.88)^{\circ}$ & $0.2505(1.28)^{\circ}$ \\
\hline Segment 12 & & $-0.5459(0.58)^{\circ}$ & $1.1263(\mathbf{3 . 0 8})^{* * * *}$ & $0.2856(1.33)^{\circ}$ & $-1.3473(0.26)^{\circ}$ & $1.1215(3.07)^{* * *}$ \\
\hline Segment 13 & & $-0.6863(\mathbf{0 . 5 0})^{* *}$ & $2.7873(\mathbf{1 6 . 2 4})^{* * *}$ & $-0.9771(0.38)^{\circ}$ & $0.8286(2.29)^{\circ}$ & $-0.2283(0.80)^{\circ}$ \\
\hline \multicolumn{7}{|l|}{ VRU (ref= no) } \\
\hline Yes & $1.0217(\mathbf{2 . 7 8})^{* * *}$ & $1.2739(\mathbf{3 . 5 7})^{* * *}$ & $-0.6937(\mathbf{0 . 5 0})^{* * * *}$ & & & \\
\hline \multicolumn{7}{|c|}{ Exclusive right $($ ref $=$ no $)$} \\
\hline Yes & $-0.1518(\mathbf{0 . 8 6})^{* *}$ & & & & & \\
\hline \multicolumn{7}{|c|}{ Speed limit $($ ref $=90)$} \\
\hline 50 & $-0.6209(\mathbf{0 . 5 4})^{* * *}$ & $-0.6153(0.54)^{* * *}$ & & & & $1.1511(\mathbf{3 . 1 6})^{* * * *}$ \\
\hline 70 & $0.1664(1.18)^{\circ}$ & $0.1513(1.16)^{\circ}$ & & & & $-0.5889(\mathbf{0 . 5 5})^{* * * *}$ \\
\hline \multicolumn{7}{|c|}{ Cycle facility (ref = grade-separated) } \\
\hline Mixed traffic & & & & & & $1.4599(\mathbf{4 . 3 1})^{* * * *}$ \\
\hline Adjacent & & & & & & $-0.3425(0.71)^{\circ}$ \\
\hline Separated & & & & & & $-0.1700(0.84)^{\circ}$ \\
\hline
\end{tabular}




\begin{tabular}{|c|c|c|c|c|c|c|}
\hline \multirow[t]{2}{*}{ Variables $^{1}$ (Continued) } & \multicolumn{6}{|c|}{ Logistic regression results at crash level $(\mathrm{N}=1295)($ Continued) } \\
\hline & $\begin{array}{l}\text { Injury crashes }^{\mathrm{a}} \\
\text { according to crash } \\
\text { type }(\mathrm{Y}=699)\end{array}$ & $\begin{array}{l}\text { Injury crashes }{ }^{\mathrm{a}} \\
\text { according to crash } \\
\text { location } \\
(\mathrm{Y}=699)\end{array}$ & $\begin{array}{l}\text { Rear-end crashes } \\
\quad(\mathrm{Y}=471)\end{array}$ & $\begin{array}{l}\text { Side crashes } \\
\quad(Y=351)\end{array}$ & $\begin{array}{c}\text { Head-on crashes } \\
(\mathrm{Y}=181)\end{array}$ & $\begin{array}{l}{\text { VRU } \text { crashes }^{\mathrm{c}}}_{(\mathrm{Y}=268)}\end{array}$ \\
\hline \multicolumn{7}{|l|}{ Signal phasing $(\mathrm{ref}=$ permitted $)$} \\
\hline Protected-only and protected/permitted & $-0.2325(\mathbf{0 . 7 9}) * *$ & $-0.2232(\mathbf{0 . 8 0}) * *$ & & & & \\
\hline Protected-only & & & $-0.2677(0.77)^{*}$ & & $-0.7673(\mathbf{0 . 4 6})^{* * *}$ & $-0.5139(\mathbf{0 . 6 0})^{* *}$ \\
\hline Protected/permitted & & & $0.514(\mathbf{1 . 6 7})^{* * *}$ & & $-0.0103(1.00)^{\circ}$ & $-0.3845(\mathbf{0 . 6 8})^{* * *}$ \\
\hline \multicolumn{7}{|l|}{ Arms $($ ref $=4)$} \\
\hline 3 & & & $0.3497(\mathbf{1 . 4 2})^{* * *}$ & & & \\
\hline \multicolumn{7}{|l|}{ Lanes $($ ref $=4)$} \\
\hline 1 & & & $0.015(1.02)^{\circ}$ & & & $0.1538(1.17)^{\circ}$ \\
\hline 2 & & & $-0.7966(\mathbf{0 . 4 5}) * * *$ & & & $-0.3603(\mathbf{0 . 7 0})^{* * *}$ \\
\hline 3 & & & $0.0113(1.01)^{\circ}$ & & & $0.6654(\mathbf{1 . 9 5})^{* * *}$ \\
\hline \multicolumn{7}{|l|}{ Median $(\mathrm{ref}=\mathrm{no})$} \\
\hline Yes & & & $-0.4030(\mathbf{0 . 6 7}) * * *$ & & $-0.1582(\mathbf{0 . 8 5}) * *$ & \\
\hline \multicolumn{7}{|l|}{ Built-up area $($ ref $=$ no) } \\
\hline Yes & & & & $0.2423(\mathbf{1 . 2 7})^{* * * *}$ & $-0.3889(\mathbf{0 . 6 8})^{* * *}$ & \\
\hline \multicolumn{7}{|l|}{$\mathrm{RLC}(\mathrm{ref}=\mathrm{no})$} \\
\hline Yes & & & & $-0.1814(\mathbf{0 . 8 3})^{* *}$ & $-0.4832(\mathbf{0 . 6 2}) * * *$ & $-0.4089(\mathbf{0 . 6 6})^{* * *}$ \\
\hline \multicolumn{7}{|l|}{ Crash severity (ref = slightly injured) } \\
\hline Unharmed & & & & & & $-2.8083(\mathbf{0 . 0 7}) * * *$ \\
\hline Dead & & & & & & $1.6745(\mathbf{5 . 3 4})^{* *}$ \\
\hline Severely injured & & & & & & $1.0825(\mathbf{2 . 9 5})^{* * * *}$ \\
\hline Hosmer and Lemeshow test ${ }^{2}$ & $\begin{array}{c}\chi^{2}=8.9597 \\
(\mathrm{df}=8, \mathrm{p}=0.3457)\end{array}$ & $\begin{array}{c}\chi^{2}=6.8137 \\
(\mathrm{df}=8, \mathrm{p}=0.5569)\end{array}$ & $\begin{array}{c}\chi^{2}=3.5617 \\
(\mathrm{df}=8, \mathrm{p}=0.8943)\end{array}$ & $\begin{array}{c}\chi^{2}=7.7375 \\
(\mathrm{df}=8, \mathrm{p}=0.4595)\end{array}$ & $\begin{array}{c}\chi^{2}=10.4146 \\
(\mathrm{df}=8, \mathrm{p}=0.2371)\end{array}$ & $\begin{array}{c}\chi^{2}=14.9971 \\
(\mathrm{df}=8, \mathrm{p}=0.0592)\end{array}$ \\
\hline Nagelkerke $\mathrm{R}^{2}{ }^{3}$ & 0.3087 & 0.2747 & 0.6332 & 0.4602 & 0.5005 & 0.5950 \\
\hline \multicolumn{7}{|c|}{$\begin{array}{l}\text { NOTE: }{ }^{1} \text { Values present the parameter estimates of the logistic regression model. For categorical variables with more than } 2 \text { categories, the category is indicated; }{ }^{2} \text { The Hosmer and Lemeshow } \\
\text { goodness-of-fit test indicates a good fit for all models; }{ }^{3} \text { The statistic indicates the error reduction of the model in percentages; } 0.3087 \text { is equal to an error reduction of } 30.87 \% \text {; Odds ratios } \\
\text { between (). Odds ratio values that are significant at } \mathrm{p} \leq 0.05 \text { are highlighted in bold. } \\
{ }^{a} \text { Due to convergence problems the variables 'crash type' and 'segment' could not be inserted in one model; }{ }^{\mathrm{b}} \text { Side crashes consist of the left-turn and right-angle crashes; } \\
{ }^{\mathrm{c}} \text { VRU crashes: crashes in which at least } 1 \text { cyclist, motorcyclist, moped rider or pedestrian is involved. } \\
* * * p \leq 0.01 \text { (significant at } 99 \% \mathrm{CI} \text { ); }{ }^{* *} \mathrm{p} \leq 0.05 \text { (significant at } 95 \% \mathrm{CI} \text { ); }{ }^{*} \mathrm{p} \leq 0.10 \text { (significant at } 90 \% \mathrm{CI} \text { ); }{ }^{\circ} \mathrm{p}>0.10 \text { (not significant at } 90 \% \mathrm{CI} \text { ) }\end{array}$} \\
\hline
\end{tabular}




\section{DISCUSSION}

The present study used an in depth crash location approach based on crash data and collision diagrams to analyze crash patterns at signalized intersections. The collision diagram information has proven to be essential and valuable for this purpose since these diagrams do not only allow to define dominant crash types but also show the pre-crash maneuvers and provides detailed information about the crash location on the signalized intersection. This crash location information was used to define 13 detailed signalized intersection segments which enabled to categorize the crash locations. This crash location approach in combination with the identification of dominant crash types and causal crash factors provides valuable insights in the nature of signalized intersection crashes and the safety impact of signalized intersection design.

Six crash types are identified of which four can be regarded as dominant signalized intersection crash types: rear-end, side, vulnerable road user and head-on crashes. These results are more or less in line with existing literature (5-8) but they identified sideswipe instead of head-on crashes as the fourth dominant crash type. Except for rear-end crashes, these crash types are also characterized by higher than average crash severity levels. Single-vehicle crashes also appear to result in less injury crashes. Since more trucks are involved in this crash type $\left(\mathrm{X}^{2}(1, \mathrm{~N}=2652)=4.338, \mathrm{p}=0.037\right)$, the lower crash severity levels can be accounted for by the higher mass of trucks which protects the truck driver from serious injuries.

In addition, the results show that the crash location is related to certain signalized intersection segments. Rear-end collisions mostly occur on the entry lanes (segment 1-3), possibly indicating differences in braking behavior between road users due to conflicting decisions in the dilemma zone. This relation between crash type and crash location on the intersection is supported by the results of another study (38) which indicated that rear-end crashes are the most common crash type at signalized intersections since the diversity of actions taken increases due to signal change. Inattentive driving of following drivers, differences between vehicles in braking performance and following too closely at the time of a signal change are identified as specific causes of rear-end crashes (39-41). As rear-end crash occurrence is related to a signal change, the presented crash pattern on the entry lanes is plausible since drivers need to be confronted with the traffic signals in order to make a conflicting decision which can result in a rear-end crash. The bypass is also prone to more rear-end crashes which can be caused by drivers yielding to vulnerable road users on the crossing facility (segment 12) or stopping to find a gap to merge with the oncoming traffic (segment 13). Since both situations result in braking movements, differences between drivers' braking performance and inattentiveness also result in more rear-end crashes at these locations. Given this crash pattern, signalized intersections should be designed to be sufficiently conspicuous. The visibility of the intersection and/or traffic signals should be improved for approaching drivers to increase their awareness. Improvements in signal coordination and optimization of change intervals also lead to a decrease in rear-end crashes (8). Segments 4-6 are dominated by side and head-on crashes. Possibly, these crashes are the result of red light running drivers approaching the intersection from opposite directions, loss of control or left-turning vehicles that are not yielding to oncoming vehicles during the permissive phase. In their observational study, Gstalter \& Fastenmeier (20) found that drivers make most errors when turning left at a signalized intersection. Therefore, driver errors can be related to the crashes in segment 6 . This emphasizes the importance of clear road design concepts that are easily understandable for road users, the so-called self-explaining roads. Since these crashes take place between crossing road users or road users approaching each other from opposite directions it is expected that they occur on the intersection plane. It is well-known that these crashes are above all the result of red-light running or unprotected left-turn phasing. As a result, possible countermeasures include the implementation of protected left-turn phasing and red light cameras even though the latter measure gives rise to increases in rear-end crashes. Additional measures such as improvements in sight distances, signal coordination and change intervals also result in less head-on and side crashes (8). Side crashes between vehicles and crossing cyclists and mopeds also characterize segments 7 and 8. Crossing the signalized intersection after the intersection plane and on the bypass seems to be more dangerous for vulnerable road users since they prevail in crashes at segments 7, 8 and 12. In general, motorists are more focused on other motorists than on vulnerable road users. Most likely, this aspect played a role in these crashes. Furthermore, conflicts between vulnerable road users and motorized vehicles still occur frequently at signalized intersections when they are not fully protected by the signal phasing (i.e. vulnerable road users have the same green phase as turning traffic). As such, potential countermeasures for vulnerable road user crashes include the implementation of protected phasing for VRUs at the crossing facilities and improved visibility for drivers approaching the crossing facilities.

The type of signal phasing influences the proportion of certain crash types. Similar to De Pauw et al. (16) and Srinivassan et al. (18) protected-only and protected/permissive left-turn signal phasing decrease the 
proportion of injury and vulnerable road user crashes. Srinivassan et al. (18) found that protected-only decreases while protected/permitted left-turn signal phasing increases rear-end crashes, which is similar to the results presented here. Possibly, protected/permitted left-turn signal phasing still results in braking or stopping maneuvers from waiting left-turning vehicles to select gaps in opposite traffic. Protected-only signal phasing also decreases the occurrence of head-on crashes since this signal phasing type prevents possible conflicts between road users.

In line with previous studies $(13,14)$, red light cameras at signalized intersections are associated with lower proportions of side and vulnerable road user crashes. The presence of red light cameras also gives rise to fewer head-on crashes since these cameras prevent red light running. However, $\chi^{2}$-tests also indicated that red light cameras result in adverse effects since they lead to increases in the number of rear-end crashes. Probably, red light cameras cause drivers to brake more abruptly in the dilemma zone since red light cameras lead to higher stopping propensities (42). As a result, conflicting decisions in the dilemma zone have a higher chance to lead to rear-end crashes.

The presence of a median results in a lower proportion of head-on crashes. Another study (12) also indicated that a median prevents vehicles from crossing into the path of oncoming traffic leading to less head-on crashes. Speed limits are significant for the proportion of injury crashes with an indication that higher speeds lead to a higher crash severity. Similar to Steinman and Hines (43), the proportion of vulnerable road user crashes is also affected by the speed limit at the signalized intersection.

At signalized intersections where cycle traffic is mixed with motorized traffic, the proportion of vulnerable road user crashes is higher. However, these differences in crash susceptibility may also be related with different cyclist volumes at the cycle facilities. Due to the lack of traffic volume data for cyclists, we were unable to test this hypothesis. Elvik et al. (4) support this hypothesis since they found that the reduction of bicycle crashes is smaller at signalized intersections with cycle lanes since cycle lanes attract more cyclists and may give rise to increased speeds among cyclists. In line with Torbic et al. (19), the proportion of vulnerable road user crashes increases with the number of lanes.

One limitation of the present study concerns the sample. The used sample of signalized intersections $(\mathrm{N}=87)$ could be a somewhat biased representation of a larger (i.e. countrywide) signalized intersection population in the sense that only intersections were included where at least one crash was registered for each year and where detailed crash data were available for. A possible bias associated herewith is a slight overrepresentation of intersections with higher numbers of crashes. However, the objective of the study was not to make inferences about the performance of signalized intersections compared to each other, but to identify crash types, locations and factors that are associated with signalized intersection crashes. The collected sample of 1295 complete crash records can considered to be valid for that purpose.

The next issue deals with the accuracy of the crash allocation. The crash location typology used to allocate the crashes to the different segments is based on simplified rules. By following this typology, the allocation of the crashes to the different segments does not fully correspond to the actual location of the crash. Despite this inconsistency, the allocation is still quite accurate since the typology is based on the impact point, the pre-crash orientation of the road users and the maneuver that the road users make (i.e the most important characteristics to reconstruct a crash). The objective of the study was not to duplicate an exact replica of each crash location but to provide insights in the crash patterns of dominant signalized intersection crashes. The developed crash location typology is assumed to be valid for this purpose since the reported crash location in the collision diagrams may also slightly deviate from the actual crash location. To assure a consistency of $100 \%$ in both crash locations, advanced in-depth crash research such as crash reconstruction techniques are required. Since most police zones in Belgium are not familiar with these techniques, the results are not greatly affected by this variation.

Another point of discussion is the cross-section design of the study. According to Hauer (44), causality cannot be reliable inferred from cross-section designs since cross-section studies compare intersections with a certain characteristic with other intersections with another characteristic. Therefore, this study design lacks the continuity that the intersection remains the same. Therefore, the possibility of confounding factors between the different intersections is not eliminated since this requires information about why a certain characteristic is present at one intersection and is absent at another (44). Since this information is often not available and difficult to account for but is required to draw cause-effect conclusions from cross-section data (44), the presence of a correlation between the proportion of crashes (the dependent variable) and certain intersection characteristics (the independent variables) is not sufficient to conclude that there is a causal relationship between both variables. 
Finally, traffic flow count data were only available for 54 of 87 signalized intersections. Previous studies indicated that AADT $(26,45,46)$ is a critical variable for crash analysis. However, this only applies to studies which aim to explain the variation in road safety performance of a sample of locations by identifying the influence of design characteristics on the level of safety. The focus of this study is to explore the crash location of dominant crash types at a typical signalized intersection. To fulfil this objective, crash data of intersections with missing AADT can be used since AADT as such is not a crucial variable to define the crash location. Because, this study does not predict crashes but merely explores available crash data by delineating the crash location on the signalized intersection itself, the lack of AADT does not present any analysis issues.

An important advantage of the crash location approach is the generalizability. The presented approach is based on a sort of 'maximal design', representing a typical signalized intersection lay-out with some extra features that are not necessarily always present but are quite common. Since, the intersection layout and characteristics may vary the approach can easily be adjusted to different designs and locations by tailoring the segments to the specific intersection or location layout in question and by adding the inherent characteristics that play a role in the crashes to the typology. For example, if researchers want to study the safety difference between signalized intersections and signed intersections (i.e. controlled with stop or yield signs), they can simply add this feature to typology.

This approach is also a useful context for exploring intersection safety since it combines crash data with collision diagram information. As such, this method combines basic in-depth crash analysis with the benefits of aggregated crash analysis leading to more reliable quantitative analysis. As a result, a more detailed insight is gained in the development and occurrence of crash types by relating crash occurrence with design characteristics of the signalized intersection. This insight is needed to assess the safety impact and possible safety issues of this intersection design which is necessary to select the appropriate countermeasure to decrease crashes.

\section{CONCLUSIONS}

The main goal of this study was to identify and analyze dominant crash types at signalized intersections by taking detailed information on the crash location into account. Some connections between certain signalized intersection crash types, their crash location and signalized intersection design characteristics have been found:

- Four dominant crash types occur at signalized intersections: rear-end, side, vulnerable road user and head-on crashes. Except for rear-end crashes, these crash types are also characterized by higher than expected crash severity levels.

- The crash location of these dominant crash types is related to specific signalized intersection segments: rear-end crashes occur mostly before the intersection or on the bypass, side and head-on crashes take mostly place on and near the intersection plane while vulnerable road user crashes occur predominantly at the crossing facilities after the intersection plane or on the bypass.

- Protected-only and protected/permissive left-turn signal phasing, exclusive turn lanes and $50 \mathrm{~km} / \mathrm{h}$ speed limits are associated with lower proportions of injury crashes.

- Characteristics associated with higher proportions of rear-end crash types are protected/permitted leftturn signal phasing and red light cameras.

- Lower proportions of head-on crashes are associated with red light cameras, protected-only left-turn signal phasing and medians.

- Red light cameras are associated with lower proportions of side crashes.

- Lower proportions of vulnerable road user crashes are associated with red light cameras and protectedonly and protected/permissive left-turn signal phasing.

- Intersection features combined with detailed signalized intersection segments as a proxy for the crash location features provide valuable insights in the nature of signalized intersection crashes and the safety impact of signalized intersection design.

\section{ACKNOWLEDGEMENTS}

This research was carried out within the framework of the Policy Research Centre Traffic Safety and was partly supported by a grant from the Research Foundation Flanders. The content of this paper is the sole responsibility of the authors. 


\section{REFERENCES}

1. Roess, R.P., E.S. Prassas and W.R. McShane. Traffic Engineering. Pearson Education, Inc., New Jersey, 2011.

2. Nuyttens, N., A. Carpentier, K. Declerq and E. Hermans. Jaarrapport Verkeersveiligheid 2012: Analyse van verkeersveiligheidsindicatoren in Vlaanderen tot en met 2012 (In Dutch).Policy Research Centre for Traffic Safety \& Belgian Road Safety Institute, 2014.

3. Ogden, K. W. Safer roads: a guide to road safety engineering. Ashgate Publishing Ltd., Melbourne, Australia, 1996.

4. Elvik, R., A. Hoye, A., T. Vaa and M. Sorensen. The handbook of road safety measures. Emerald Group Publishing Limited, Bingley, United Kingdom, 2009.

5. Chandler, B. E., M. C. Myers, J. E. Atkinson, T. E. Bryer, R. Retting, J. Smithline, ..., P. Izadpanah. Signalized Intersections Informational Guide: Second Edition. Publication FHWA-SA-13-027, FHWA, U.S. Department of Transportation, 2013.

6. Abdel-Aty, M., C. Lee, X. Wang, J. Keller, S. Kowdla, and H. Prasad. Identification of intersection's crash profiles/patterns. University of central Florida, Department of Civil and Environmental Engineering, 2006.

7. Ogden, K. W., and S. W. Newstead. Analysis of crash patterns at Victorian signalized intersections. Publication No.60, Accident Research Centre, Monash University, 1994.

8. Antonucci, N. D., K. Kennedy Hardy, K. L. Slack, R. Pfefer, and T. R Neuman. (2004). Volume 12: A Guide for Reducing Collisions at Signalized Intersections. Publication NCHRP 500, Transportation Research Board, 2004.

9. Abdel-Aty, M., and J. Keller. Exploring the overall and specific crash severity levels at signalized intersections. Accident Analysis \& Prevention, Vol. 37, No.3, 2005, pp. 417-425.

10. Ye, X., Pendyala, R., F. Al-Rukaibi, and K. Konduri. A joint model of crash type and severity for twovehicle crashes. DVD. In proceedings of $87^{\text {th }}$ Annual Meeting of the Transportation Research Board. Washington DC, USA, 2008.

11. Wang, X. Safety analysis at signalized intersections considering spatial, temporal and site correlation (PhD thesis). University of Central Florida, Florida, 2006.

12. Keller, J., M. Abdel-Aty, and P. Brady. Type of collision and crash data evaluation at signalized intersections. ITE Journal, Vol. 76, No.2, 2006, pp. 30-39.

13. De Pauw, E., S. Daniels, T. Brijs, E. Hermans, and G. Wets. To brake or to accelerate? Safety effects of combined speed and red light cameras. Journal of Safety Research, Vol. 50, 2014, pp.59-65.

14. Høye, A. Still red light for red light cameras? An update. Accident Analysis \& Prevention, Vol. 55, pp. 77-89.

15. Shin, K., and S. Washington. The impact of red light cameras on safety in Arizona. Accident Analysis and Prevention, Vol. 39, No. 6, 2007, pp.1212-1221.

16. De Pauw, E., S. Daniels, S. Van Herck, and G. Wets. The traffic safety effect of protected left-turn phasing at signalized intersections. Submitted, 2013.

17. Srinivasan, R., C. Lyon, B. Persaud, J. Baek, F. Gross, S. Smith and C. Sundstrom. Crash Modification Factors for Changes to Left-Turn Phasing. In Transportation Research Record: Journal of the Transportation Research Board, No. 2279, Transportation Research Board of the National Academies, Washington, D.C., 2012, pp.108-117.

18. Garder, P., L. Leden, and T. Thedeen. Safety implications of bicycle paths at signalized intersections. Accident Analysis \& Prevention, Vol. 26, No.4, 1994, pp. 429-439.

19. Torbic, D., D. Harwood, C. Bokenkroger, R. Srinivasan, D. Carter, C. Zegeer, and C. Lyon. Pedestrian Safety Prediction Methodology for Urban Signalized Intersections. In Transportation Research Record: Journal of the Transportation Research Board, No. 2198, Transportation Research Board of the National Academies, Washington, D.C., 2011, pp. 65-74.

20. Gstalter, H., and W. Fastenmeier. Reliability of drivers in urban intersections. Accident Analysis and Prevention, Vol. 42, No.1, 2010, pp. 225-234.

21. Retting, R. A., H.B. Weinstein, and M.G. Solomon. Analysis of motor-vehicle crashes at stop signs in four U.S. cities. Journal of Safety Research, Vol. 34, No.5, 2003, pp. 485-489.

22. Polders, E., S. Daniels, W. Casters, and T. Brijs. Identifying crash patterns on roundabouts. Traffic Injury Prevention, Forthcoming. 
23. McCartt, A. T., V.S. Northrup, and R.A. Retting. Types and characteristics of ramp-related motor vehicle crashes on urban interstate roadways in Northern Virginia. Journal of Safety Research, Vol. 35, No.1, 2004, pp.107-114.

24. Khattak, A., \& Targa, F. (2004). Injury Severity and Total Harm in Truck-Involved Work Zone Crashes. In Transportation Research Record: Journal of the Transportation Research Board, No. 1877, Transportation Research Board of the National Academies, Washington, D.C., 2004, pp.106-116.

25. Kweon, Y. Crash data sets and analysis (chapter 8). In Handbook of Traffic Psychology, pp. 97-105. Academic Press, London, United Kingdom, 2011.

26. Reurings, M., T. Janssen, R. Eenink, R. Elvik, J. Cardosa, and C. Stefan. Accident Prediction Models and Road Safety Impact Assessment: a state-of-the-art. Publication deliverable No.1, RIPCORDISEREST, Federal Highway Research Institute, 2006.

27. Nambuusi, B. B., T. Brijs, and E. Hermans. A review of accident prediction models for road intersections. Publication RA-MOW-2008-004. Policy Research Centre for Traffic Safety, 2008.

28. Massie, D., K. Campbell, and D. Blower. Development of a collision typology for evaluation of collision avoidance strategies. Accident Analysis \& Prevention, Vol. 26, No.3, 1993, pp. 241-257.

29. Al-Ghamdi, A.S. Using logistic regression to estimate the influence of accident factors on accident severity. Accident Analysis \& Prevention, Vol.34, 2002, pp. 729-741.

30. Yan, X.D., E. Radwan, and M. Abdel-Aty. Characteristics of rear-end accidents at signalized intersections using multiple logistic regression model. Accident Analysis \& Prevention, Vol. 37, No.6, 2005, pp. 983-995.

31. Yau, K.K.W. Risk factors affecting the severity of single vehicle traffic accidents in Hong Kong. Accident Analysis \& Prevention, Vol.36, No.3, 2004, pp.333-340.

32. Zhang, J., J. Lindsay, K. Clarke, G. Robbins, and Y. Mao. Factors affecting the severity of motor vehicle traffic crashes involving elderly drivers in Ontario. Accident Analysis \& Prevention, Vol. 32, No.1, 2000, pp. 117-125.

33. Huiqin Chen H., L. Libo Cao, and D.B. Logan. Analysis of Risk Factors Affecting the Severity of Intersection Crashes by Logistic Regression, Traffic Injury Prevention, Vol.13, No.3, 2012, pp. 300307.

34. Allison, P.D. Logistic Regression Using SAS: Theory and Application. SAS Institute Inc., Cary, NC, 1999.

35. Field, A. Discovering statistics using SPSS. SAGE Publications Ltd., London, United Kingdom, 2009.

36. Heinze, G., and M. Schemper. A solution to the problem of separation in logistic regression. Statistics in Medicine, Vol. 21, No. 16, 2002, pp. 2409-2419.

37. O'Brien, R.M. A Caution Regarding Rules of Thumb for Variance Inflation Factors. Quality \& Quantity, Vol. 41, No. 5, 2007, pp. 673-690.

38. Yan, X., E. Radwan and M. Abdel-Aty. Characteristics of rear-end accidents at signalized intersections using multiple logistic regression model. Accident Analysis \& Prevention, Vol. 37, No.6, 2005, pp. 983-995.

39. Abdel-Aty, M. and H. Abdelwahab. 2004. Modeling rear-end collisions including the role of driver's visibility and light truck vehicles using a nested logit structure. Accident Analysis \& Prevention, Vol. 36, No.3, 2004, pp. 447-456.

40. Strandberg, L. Winter braking tests with 66 drivers, different tires and disconnectable ABS. Presented at International Workshop on Traffic Accident Reconstruction, Tokyo, 1998.

41. Sayer, J., M. Mefford, and R. Huang. The effect of lead-vehicle size on driver following behavior. Technical Report No. UMTRI-2000-15. , Transportation Research Institute, Michigan University, 2000.

42. Lum, K. M., and Y. D. Wong. A Before-and-After Study of Driver Stopping Propensity at Red Light Camera Intersections. Accident Analysis and Prevention, Vol. 35, No. 2, 2003, pp. 111-120.

43. Steinman, N. and K. Hines. A Methodology to Assess Design Features for Pedestrian and Bicyclist Crossings at Signalized Intersections. DVD. In proceedings of $83^{\text {rd }}$ Annual Meeting of the Transportation Research Board. Washington DC, USA, 2004.

44. Hauer, E. Cause, effect and regression in road safety: A case study. Accident Analysis \& Prevention, Vol.42, No.4, 2010, pp.1128-1135. 
45. Chin, H. and M. Quddus. Applying the Random Effect Negative Binomial Model To Examine Traffic Accident Occurrence at Signalized Intersections. Accident Analysis and Prevention, Vol. 35, No. 2, 2003, pp. 153-159.

46. Liu, P. and H. Young. A Neural Network Approach on Studying the Effect of Urban Signalized Intersection Characteristics on Occurrence of Traffic Accidents. DVD. In proceedings of $83^{\text {rd }}$ Annual Meeting of the Transportation Research Board. Washington DC, USA, 2004. 